\title{
OBSERVACIONES SOBRE EL GÉNERO DRAMÁTICO: \\ EL CIERREY LA APERTURA \\ DE LA DEVOCIÓN DE LA CRUZ
}

Isaac Benabu

Universidad Hebrea de Jerusalén 91905, Monte Escopo, Jerusalén

Israel

benabu@mail.huji.ac.il

El presente artículo se divide en dos partes:

- la primera enfoca aspectos de la teatralidad que ayudan a identificar la evaluación del género de una obra y servirá de base a la argumentación presentada en la segunda parte;

- la segunda analiza la dramaturgia de Calderón en La devoción de la cruz, su organización del material dramático fijándose en la construcción del cierre y luego de la apertura. En particular me refiero a esos aspectos que ayudan a determinar el género de la obra; el progreso de la acción, el ambiente sobre las tablas y la caracterización de algunos de los personajes.

1.

Por evidente que parezca la siguiente observación, la aproximación a una obra, sea tragedia que comedia cómica, se centra sobre la teatralidad de dicha obra, pues está compuesta para ser representada. Como he 
afirmado en otro trabajo ${ }^{1}$, la escritura teatral se diferencia de la escritura literaria por ser espacial, espacios que el propio dramaturgo deja en su texto pues sabe que va dirigido a actores que los completarán ${ }^{2}$. En muchos casos lo hacen después de haber examinado las instrucciones incluídas en el texto por el propio dramaturgo.

Lo dicho constituye una consideración de base que recuerda lo que Lope recomienda al principio de su Arte nuevo cuando se refiere con ironía a los académicos que creen conocer mejor las comedias basándose solo en textos que lo que el mismo Lope pudiera creando y representándolas:

Fácil parece este sujeto [escribir un arte de comedias],

fuera para cualquiera de vosotros, y fácil

que ha escrito menos de ellas, y más sabe

del arte de escribirlas y de todo;

que lo que a mí me daña en esta parte

es haberlas escrito sin el arte. (p. 11)

Cabría recordar en breve ciertas características teatrales que distinguen los dos géneros, tragedia y comedia cómica, y que se observan en el proceso de construir una obra para ser representada. Tendremos en cuenta parámetros teatrales para la construcción de una representación que se sonsacan de una lectura del texto:

1) En primer lugar, me refiero al efecto del final de una obra que nos ayuda a distinguir entre tragedia y comedia cómica: si termina en catástrofe, será tragedia. En el caso de la comedia cómica el desarrollo de la acción culmina en conciliación.

2) En ambos géneros el desarrollo de la acción se produce como un movimiento musical; una corriente que fluye durante toda la obra una vez determinada la clave del movimiento en la apertura.

3) Consideremos también el ambiente que se produce sobre las tablas desde el inicio de la acción por el cual el dramaturgo invita la partici-

${ }^{1}$ Para una discusión de los factores que influyen sobre la lectura teatral, ver Benabu, 2015, p. 233. 64-66.

${ }^{2}$ Sobre el reto que la apertura presenta para el dramaturgo, ver Benabu, 2003, pp. 
pación de los espectadores. En el caso de la tragedia se crea un ambiente serio y en ocasiones inquietante, de creciente intensidad y seriedad; y mediante la complicación de la trama atrae la atención del espectador haciéndole sentir emociones fuertes por todo cuanto se produce sobre las tablas (frecuentemente por medio de la ironía dramática), dándole a entender lo inexorable del desarrollo de la trama. Tras una concienciación paulatina del peligro que amenaza, el espectador se cerciorará que no habrá solución posible al conflicto presentado, o sea a la catástrofe del final. Frecuentemente la obra terminará en muerte o separación perpetua.

Al contrario, en muchas comedias cómicas la acción se inicia con un ambiente ligero que pudiera invitar la risa. Los enredos no serán menos complicados que los que se producen en una tragedia. Sin embargo, el ambiente creado por el tipo de enredo se mantiene en un nivel divertido. El espectador, distanciado de lo que se desarrolla sobre las tablas y captando los enredos con más claridad de la que pudieran ejercer los personajes, se divierte. Todo conduce a una resolución que termina en conciliación (matrimonio o reunión de personajes extraviados, etc.).

Como ejemplo, tomemos el desarrollo del tema del honor en ambos géneros: en la tragedia el honor produce situaciones graves (sospechas mal fundadas que conducen a actos violentos al final), mientras que en la comedia cómica el honor produce situaciones que, por amenazantes que parezcan, siempre encuentran salida para que todo se resuelva al final, satisfaciendo las expectativas del espectador.

4) En cuanto a la caracterización de los personajes, en el caso de la tragedia los personajes serán complejos y matizados, afrentando conflictos por los cuales adquieren profundidad a medida de que la acción se desarrolla. En la comedia cómica, con frecuencia los personajes son uni-dimesionales y carecen de matices (a menudo son estereotipos), y se exageran ciertos apectos del personaje para hacerle aparecer ridículo frente al espectador. Pienso en esa divertidísima apertura de El lindo don Diego con que Moreto presenta al protagonista ridículo de su obra.

Prosigamos aclarando ciertos aspectos de la comedia cómica. Lope recomienda en su Arte nuevo que la comedia aúrea contiene mezcla 
«de risa y llanto» ${ }^{3}$. Indudablemente en la mayoría de los casos la comedia cómica produce risa ${ }^{4}$. Sin embargo la risa como efecto que define lo producido por este sub-género dramático no parece ser una clasificación suficientemente abarcadora y específica puesto que en las tragedias también se producen secuencias que provocan risa ${ }^{5}$. Mas bien se determina la clave del movimiento (mencionado en el punto 2 más arriba) al iniciar la obra, la cual se va desarrollando a lo largo para culminar en un desenlace que produce el ambiente de conciliación al finalizar. Me refiero al efecto de alivio y satisfacción que la comedia cómica suele inspirar en el espectador cuando los enredos se resuelven felizmente.

Repito: al investigar la comedia cómica de Calderón, habría que aludir en primer lugar al efecto o efectos producidos por el final de una obra. Con esta información, hemos de volver al texto para construir el ambiente que se crea sobre las tablas desde que incia la acción, y ver cómo se encamina el desarrollo de la acción para que suscite el efecto deseado en el espectador. Esta sería pues una regla general para aclarar el género de una obra; y por supuesto, esto no quita la posibilidad de que se invierta una convención para sorprender al espectador. Es un privilegio concedido al dramaturgo que intenta ganarse al espectador revolcando lo aceptado, lo convencional ${ }^{6}$.

Y para concluir la discusión sobre los aspectos generales que

${ }^{3}$ En realidad el orden de las palabras de Lope más se refiere a la tragedia aúrea que a la comedia cómica, pues las comedias cómicas no suelen terminar en llanto, a menos que no sea parodiando el llanto.

${ }^{4}$ Tengamos en cuenta lo indicado por Olson: «The comic action does not consist wholly in comic incidents; it is comic not in virtue of each and every part being comic but in virtue of it being comic as a whole [énfasis de Olson]» (1968, p.40). También la importancia de definir los tipos de risa, como apuntó acertadamente el colega Ignacio Arellano en una conversación.

${ }^{5}$ Pensemos en Coquín, el gracioso de El médico de su honra que durante varias secuencias de la obra es un instrumento de donaire, pero que a medida de que la trama se complica y llegamos a la tercera jornada, deja de ser gracioso para expresar sus propios temores frente al Rey — no obstante la amenaza a sus propios dientes-, hablando con mucha seriedad para advertir el peligro que amenaza la vida de Mencía).

${ }^{6}$ Un buen ejemplo sugerido por Felipe Pedraza, en una conversación durante el congreso, es el hecho de que al principio de Marta la piadosa de Tirso la protagonista salga enlutada, vestida de negro, pronunciando versos que describen su desesperación:

Mas a mí la esperanza de mis males

de tal modo me aflige y desespera

que no puedo esperar ni aun esperanza. (I, vv. 12-14) 
hemos aducido sobre el análisis de la teatralidad de una obra, más que las consideraciones teóricas aplicadas a textos clásicos ${ }^{7}$, observamos que, entre los grandes dramaturgos del renacimiento como Shakespeare, Lope, Calderón y Tirso, la práctica teatral en la construcción del final de una obra mantiene una distinción entre la tragedia y la comedia ${ }^{8}$.

2.

Al enfrentarse con los argumentos sobre el género dramático de $\mathrm{La}$ devoción de la cruz, supongo que se podría deducir de cuanto Aristóteles ha escrito que la tragedia es género aristocrático, y la comedia género popular. Será por esto, tal vez, que algunos estudiosos hayan considerado

Todo lo cual haría pensar que la pérdida de un hermano, que las dos hermanas lloran, invita seriedad. Sin embargo, ya en el verso 50 se manifiesta claramente que tanto el luto como el llanto de su hermana Lucía son disimulos que no se atribuyen a la muerte del hermano:

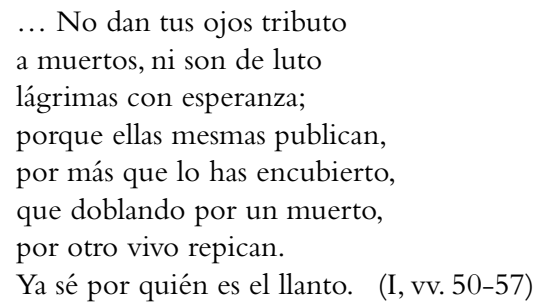

La construcción de la apertura deberá pues comunicar al espectador, no un ambiente de duelo, como parece aparentar la vestidura de las hermanas: todo lo opuesto. Como lo indica Marta la tristeza es fingida. Cabría considerar también que en tal caso, lo cómico vendría a resaltar bien antes del verso 50, si las actrices que protagonizan el cuadro son conocidas por el público como actrices cómicas - consideración teatral que empieza por imponerse en la elección de actores y en el proceso de construcción que irá desarrollándose en el curso de los ensayos. Sobre una interpretación de la comicidad de Marta la piadosa, ver Arellano, 1989.

${ }^{7}$ Me refiero a lo que Aristóteles ha escrito sobre la posibilidad de componer una tragedia con «felice fin» en el cap. 14 de su Poética. Con todo, el ejemplo que elijió para ejemplificar detalladamente su concepción de la tragedia es el Edipo Rey de Sofocles, cuyo fin no deja duda acerca del final catastrófico de la acción dramática.

${ }^{8}$ Además el análisis de la comedia renacentista ya se ha llevado a cabo en otros ámbitos académicos. En el caso de Shakespeare, las llamadas "problem comedies» han sido clasificadas como perteniecientes al género cómico, donde la risa no es un factor imprescindible, como no lo es, p. ej. al final de El mercader de Venecia donde el ambiente de conciliación creado por los matrimonios confirma el género cómico. 
la tragedia como género más apropiado cuando la obra trata de asunto devocional, y muchos han querido identificar La devoción de Calderón como tragedia, incluso cuando su autor ha declarado claramente al finalizar la obra que no lo es.

Así que empecemos citando las palabras del mismo Calderón y con las que da fin a La devoción. ¿Qué reacción está pidiendo, nos preguntamos? Me refiero a dos ediciones del siglo Xvir que llevan el título de la comedia y que varían en las palabras empleadas para marcar el final de la obra, pero no en el sentimiento que tales palabras comunican. En la Parte 28 de comedias de varios autores de Huesca, 1634, el texto reza:

\author{
Y con el fin \\ de tan grande admiración, \\ La devoción de las cruz \\ felice acaba su autor.
}

Y en la Primera parte de comedias de Calderón de 1636, así corre el texto:

\author{
Y con el fin \\ de tan grande admiración \\ La devoción de la cruz, \\ da felice fin su autor?.
}

No podremos ignorar la nota de celebración que coincide en las dos ediciones ${ }^{10}$. Es más, quien pronuncia estas palabras es Curcio, que dejando de ser personaje al finalizar la obra, reasume su papel de actor, para comunicar el fin conciliador indicado por el propio dramaturgo en las palabras citadas arriba y olvidando el papel de padre enojado y frustrado que representó en el último cuadro.

Sin duda alguna, las palabras que cierran la obra apelan al público que celebre el "felice fin", pues Eusebio, aunque muerto, ha conseguido confesar sus pecados y ha tenido una muerte dulce que anuncia su salvación; mientras que Julia, asaltada por el enfurecido padre, agarra la cruz que la salva de las garras de Curcio. Un público católico, y no sólo

\footnotetext{
${ }^{9}$ Las citas empleadas en este artículo se refieren a la edición de Wexler.

10 ¡Descartemos, por supuesto, que ese «felice acaba su autor» en la edición de Huesca se refiera al alivio que sintió Calderón al deshacerse de su obra!
} 
del siglo diez y siete, no pudiera menos que celebrar la salvación de Eusebio y el rescate de Julia, ¿no es así?

Voy a enfocar, pues, sobre La devoción de la cruz, obra que traté casi al inicio de mi carrera, para subrayar como el título de la obra tanto como los retratos de Calderón han llegado a influir profundamente en la crítica ${ }^{11}$.

Muy brevemente la acción de La devoción podría resumirse de la siguiente manera. El comportamiento de un padre tiránico y airoso pone en peligro la vida de sus hijos, conocidos o por conocer. El hijo desconocido, cuya constante devoción a la cruz le salva de los muchos peligros que le amenazan, se convierte en bandolero justamente por no conocer su propia identidad.

No hay por qué aludir a la copiosa bibliografia que existe sobre La devoción pues es bien conocida. Basta mencionar las dos tendencias que han surgido: una considera que quien está al centro de la acción es Curcio $^{12}$ y la otra Eusebio ${ }^{13}$, pero las dos califican la obra como tragedia $^{14}$. La consideran como tal porque sitúan al protagonista, sea el uno que el otro, en una acción que finaliza con la frustración del uno o la muerte del otro.

La conclusión sacada en el citado artículo de Parker parece basarse en parte en palabras pronunciadas por Curcio en la tercera jornada. Cito:

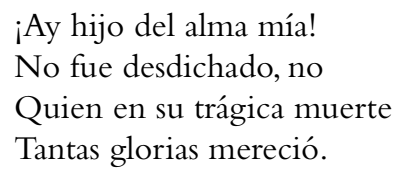

(III, vv. 770-773)

\footnotetext{
${ }^{11}$ Ver Benabu, 1988 y 2003. Otra consideración que, aunque parezca periférica ahora, tiene su lugar en este artículo: el aspecto fisico de Calderón en los retratos que dél nos han llegado. Estamos tan acostumbrados a contemplar esa mirada solemne, severa incluso. El congreso celebrado en estas Actas se propone examinar lo cómico en las obras de nuestro dramaturgo y esto es particulamente grato ya que, pese a esa expresión grave, se propone aquí apuntar al sentido del humor del dramaturgo.

${ }^{12}$ Parker, 1957, p. 2.

${ }^{13}$ Pring-Mill, 1968, pp. 386-388.

${ }^{14}$ Parker, 1962, p. 227.
} 
Para Curcio la muerte de Eusebio resulta trágica, como lo afirma el texto citado, aunque, habiendo presenciado su milagrosa resurrección, reconoce que la manera en que muere merece «tantas glorias». Sin embargo el espectador percibe las palabras de Curcio con la percepcíon más amplia del personaje que ha formada a lo largo de la obra. Cuando oye a Curcio llorar su situación en el citado texto, no podrá ignorar que lo que le acaece al personaje es debido a su carácter áspero, que le ha llevado a cometer una serie de acciones impulsivas dirigidas tanto a Julia, como a su propia esposa.Y la percepción del espectador se verá confirmada cuando Curcio, cuyo arrepentimiento resulta bastante efimero, se lanza sobre su hija con violencia al final de la obra ${ }^{15}$.

Más recientemente, Manuel Delgado ha vuelto a la obra y opina que la obra es trágica, implicando que la crítica anterior no ha prestado suficiente consideración al contexto cultural e histórico en que Calderón componía sus obras teatrales, tal vez "por el credo religioso de un lector particular» ${ }^{16}$. A una conclusión semejante llega Adrián Sáez, repitiendo las recomendaciones de Delgado ${ }^{17}$. Sin haber puesto en discusión lo problemático del género de la obra, los citados y otros han adoptado teorías previas basándose en lecturas de la obra, acumulando una serie de datos textuales y argumentos paratextuales, e ignorando a la vez consideraciones de orden teatral que se encuentran en el texto, o bien expícita o implícitamente.

Es posible que los críticos que han estudiado esta obra anterirormente se hayan dejado llevar tanto por sus propias creencias religiosas como por esa expresión seria y esa vestidura eclesiástica de Calderón en los ya citados retratos. Recordemos que nuestro dramaturgo escribió un número mayor de comedias cómicas que de dramas o tragedias, comedias ricas en ingenio que provocan risa y satisfacción en el público. También se han creado confusiones al momento de interpretar La devoción aplicando convenciones que más tienen que ver con la novela que con el teatro, y donde se comparan componentes dramáticos que apa-

15 Otros estudiosos han seguido la corriente a Parker y a Pring-Mill.

16 «Es necesario tener en cuenta las condiciones culturales y religiosas en que se escribieron La devoción de la cruz y las comedias de santos y bandoleros para no reducir su posible significado al horizonte de expectatitivas creado por la cultura y el credo religioso de un lector particular» (Delgado, 1997, p. 51).

17 «El conjunto del teatro aúreo debe leerse e interpretarse desde los parámetros del momento, sin olvidar el pacto de lectura y convenciones genéricas de cada obra» (Delgado, 1997, p. 219). 
recen en otras obras calderonianas pero en diferentes contextos, y que producen efectos teatrales totalmente diferentes. Me refiero a ciertas secuencias en La devoción que parecen haber traído a la mente las tragedias de honor de Calderón, con efectos bien distintos. Una obra es una creación cerrada, en el sentido que su significado ha de juzgarse dentro los límites de la obra misma, sin tener que aclarar «problemas» aludiendo a situaciones en otras obras que acaban por no parecerse del todo.

Empleando un método que he recomendado en otro trabajo ${ }^{18}$, el de leer desde el final al principio, construyamos las secuencias en los últimos cuadros. Luego veremos qué repercusiones tienen para comprender la acción desde su inicio, pues, como he dicho con frecuencia, el final de una obra es necesariamente el punto más iluminador para empezar a construir la acción. Así mismo lo es para descifrar la caracterización de los personajes ya que en ese punto es donde toda la acción culmina y se resuelve.

Pero dejemos la teoría de lado para fijarnos más detalladamente en el fin de La devoción. Eusebio muere a los pies de su padre Curcio, y éste llora la muerte de un hijo desconocido por él. Alberto regresa y reanima el cuerpo inerte de Eusebio dándole suficiente tiempo para que se confiese y reciba absolución, lo cual garantiza su salvación. Eusebio muere una segunda vez y Alberto hace la señal de la cruz sobre su cuerpo. Gil, Curcio y Julia, que observan lo sucedido desde otro punto de la escena, quedan tan maravillados como también el espectador por lo que han presenciado. Calderón define este cierre de «tan grande admiración». Pero es una equivocación opinar que los sentimientos que estas secuencias despiertan consisten en el admiratio que Aristóteles relaciona con los efectos del miedo y piedad que marcan el final de una tragedia. Las circunstancias milagrosas implícitas en la muerte de Eusebio ciertamente producen en el espectador a la vez alivio y admiración por ese fin milagroso, ya que Eusebio se salva y es de suponer que su alma llega al cielo. Lo que es más, el espectador nunca presencia a Eusebio en enfrentamientos puramente violentos, aunque haya llevado una vida de bandolero, pues esos actos más bien se relatan que se observan; el duelo de la primera jornada siendo la única excepción, secuencia a la que volveré más tarde. En efecto, lo que el espectador ve es un galán apasionadamente enamorado de Julia, pero que, por ignorar su paternidad, se encuentra deprivado de la protección que una familia noble le hubiera

${ }^{18}$ Benabu, 2015, p. 233. 
ofrecido; uno que a lo largo de su joven vida ha sido perseguido por fuerzas que han buscado vencerle. Recordemos que tras ver la señal de la cruz en el pecho de Julia, demuestra también su capacidad de frenar sus instintos. Al final se salva de las desgracias que le acaecen por su firme y natural devoción a la cruz.

Consideremos ahora argumentos de índole teatral: el 'blocking' o la posición de los personajes sobre el escenario en el último cuadro. Hemos dicho que Curcio, Julia y Gil observan las dos muertes de Eusebio desde un punto opuesto del escenario; sin embargo Calderón no ha indicado la posición de Alberto. Lo que intuímos es que éste se acerca a los tres personajes meniconados para anunciar la muerte y redención de Eusebio, y es de suponer que se encuentra cerca del sepulcro de Eusebio, que una acotación del cuadro anterior sitúa en el lugar central al fondo del tablado del corral, lugar propio de los descubrimientos. Curcio y los demás personajes se encuentran más al frente. Curcio, enternecido momentáneamente por el respeto que Eusebio dice sentir por él al enfrentarse los dos, luego cae en un estado de profundo duelo al darse cuenta de que el que ha muerto es nada menos que su hijo. Es cierto que el estado de ánimo de Curcio podría considerarse en otro contexto como material trágico, si no fuera por lo superficial que resulta a la luz de la violencia con que amenaza a Julia apenas 19 versos más tarde. Sin embargo, Julia, sintiendo el poder redentor de la cruz manifestado por la muerte de su hermano, cobra confianza al ver que Eusebio se salva al morir, y confiesa un catálogo de maldades cometidas por ella (claro que maldades cometidas a espaldas del espectador pues parecen no cuadrar con la impresión creada por este personaje en el resto de la obra), y se entrega a la merced ofrecida por la cruz. Por otra parte Curcio, aparentemente recuperado de su dolor por la muerte de Eusebio, se repone repentinamente al oír la confesión de Julia, y vuelve a encarnar el personaje violento y airoso que presenciamos varias veces en el curso de la obra: repito un cambio que sucede en apenas 19 versos. Imaginando impulsivamente que su hija le ha deshonrado, tal como había hecho anteriormente con su mujer (II, vv. 380-400), Curcio se lanza contra ella con la misma furia que le vimos demostrar hacia Eusebio en un cuadro anterior. El texto explicita claramente los gestos que el actor ha de adoptar al oír las palabras de Julia:

¡Oh asombro de las maldades!

Con mis propias manos hoy 
te mataré, porque sea

tu vida y tu muerte atroz.

(III, vv. 795-797)

La acotación que sigue confirma que Julia se salva del asalto violento del padre, frustrando la acción de Curcio y dejándole con los brazos extendidos pero vacíos: actitud que podría resultar ridícula y que más bien provocaría la risa del espectador junto con el alivio que éste siente al ver que Julia se encuentra a salvo. Por éstas y otras acciones de Curcio a lo largo de la obra, resulatría difícil sentir compasión por un personaje que Calderón ha alejado de la tragicidad.

Pasemos ahora a construir la obra desde el final al principio, método característico de la lectura teatral, y consideremos que al componer la apertura Calderón ha querido distanciar al espectador de la verisimilitud. En ese cuadro participan dos graciosos rústicos, uno de los cuales, Gil, pronuncia un discurso que parodia un soliloquio sobre el tema del honor, discurso pronunciado en general por el protagonista de una tragedia: sólo que en este caso Gil lo dirige a su burra (vv. 60-80). La apertura crea, pues, el ambiente para la recepción de una comedia cómica ${ }^{19}$.

El segundo cuadro abre con un duelo entre dos galanes, como los que encontramos en tantas comedias de capa y espada. Lisardo, sacando su espada, amenaza a Eusebio pero deteniéndose antes para identificarse frente a su rival, lo cual hace en 72 versos. Acabados éstos, es Eusebio ahora quien detiene la acción del duelo pronunciando un discurso que relata la historia de su vida en no menos de 167 versos.Y cuando por fin reemprenden el duelo y Eusebio hiere mortalmente a Lisardo, responde a la petición de su rival echándosele a cuestas y llevándoselo a que se confiese antes de morir. Lo cómico de la escena viene delineada por la reacción del gracioso que observa el duelo desde su escondite: «Matarlo y llevarlo a cuestas!» (I, v. 404) exclama Gil asombradísimo. Y luego cuando cuenta lo que acaba de presenciar a sus compañeros dice, refiriéndose a Eusebio: «Matóle y cargo con él; / sin duda a salar le lleva.» (I, vv. 413-414) ¿Cuál pudiera ser la reacción del público a este comportamiento tan sorpendente en una escena de duelo sino risa al oír los comentarios de Gil?

19 Ver Varey: «El elogio de la burra que hace Gil es también satírico... y sirve para introducer de manera burlesca el tema del honor» (1973, p. 156). 
Luego en el tercer cuadro se presenta a un Curcio airoso y tiránico, personaje que se califica en varias secuencias como pertenciente a un melodrama más bien que a una tragedia, pues su carácter carece de matices. Quiere forzar a Julia que se sepulte en un convento, sin dar crédito a las prudentes protestas de su hija. Así se pronuncia:

\section{Sola mi voluntad \\ en lo justo y lo injusto \\ has de tener por tu gusto.}

(I, vv. 583-585)

También a través de las dos primeras jornadas, Curcio nos explica en discursos interrumpidos que volviendo de una ausencia de ocho meses, concluye impulsivamente que su preñada esposa le ha engañado. Ridículo, pues parece habérsele olvidado que la gestación suele durar nueve meses, incluso en el siglo diez y siete, y que por lo tanto pudo haber engendrado a los mellizos antes de ausentarse de su mujer. Cálculo que le pone en ridículo, repito, junto con su igorancia de los hechos de la vida, inexcusable en un padre que ya había engendrado a Lisardo. En la comedia cómica, hay un sinfín de padres que se oponen a respetar los deseos de sus hijos. Al fin y al cabo, tanto por su desenfrenado comportamiento en la primera como en la tercera jornada, Curcio se asemeja más bien al senex de la comedia romana que al protagonista de una tragedia donde la construcción del personaje es mucho más compleja. Muy al revés de crear un ambiente de tragedia sobre las tablas, los tres primeros cuadros de la apertura definen el marco receptivo como perteneciente a la comedia cómica ${ }^{20}$.

También lo hace la organización del material dramático. Durante la primera jornada, la acción se desarrolla a un paso casi vertiginoso. Podría decirse que las secuencias que se encuentran en la primera jornada pudieran fácilmente acomodar la acción de toda una obra: en la primera secuencia, exposición; en la segunda complicación y en la tercera resignación. En esa primera jornada encontramos como tema de exposición el amor prohibido entre Eusebio y Julia. La acción se complica mediante la muerte de Lisardo en el duelo entre él y Eusebio, la cual imposibilita la continuación de la relación entre Eusebio y Julia, pues Eusebio tiene que exiliarse. E incluso esa resignación que frecuen-

\footnotetext{
${ }^{20}$ Sobre el término «marco de recepción» ver Benabu, 2003, p. 66.
} 
temente marca la tercera jornada de una tragedia aquí se incluye en la primera cuando los amantes tienen que separarse por una situación que no ofrece alternativa alguna ${ }^{21}$.

Volvamos una vez más a ese recurso del propio Calderón que juega con la teatralidad del final de La devoción, cuando el dramaturgo hace renunciar la identidad teatral al personaje que pronuncia los últimos versos de la obra, es decir a Curcio, para mostrarse frente al público como simple actor. Si Calderón hubiese intentado que su obra terminase en tragedia, parece extraño que el personaje trágico se desenmascarase frente al público para calificar el ambiente en las tablas de «felice». No conozco otro personaje calderoniano, que al ser trágico, comprometa el ambiente trágico del final empleando un recurso parecido por medio de la palabra o el gesto ${ }^{22}$. Lo que es más, con el final que ha dibujado para La devoción, Calderón ha abandonado ese sentido de acercamiento entre las tablas y los espectadores que exige la tragedia, dándole al contrario lo que pudiéramos calificar de un fin de fiesta, donde los personajes más bien se distancian del público como personajes ficticios para presentarse desde las tablas como lo que son, actores.

Lo aportado hasta aquí me hace pensar, dado el paso acelerado de la acción y los constantes cambios de ambientación sobre las tablas, así como la caracterización sin matices de Curcio, que el interés de Calderón conisistió en enfocar su obra según las características de la comedia cómica. En La devoción de la cruz, Calderón nos ha brindado una ficción elaborada sobre el modelo hagiográfico, que ilumina la tesis central de toda la obra. La exaltación dada a la cruz a lo largo de la obra, la cual se convierte casi en personaje al final cuando se lleva a Julia "a lo alto de la escena», demuestra su potencia como símbolo teatral.

El ambiente de La devoción sobre las tablas, incluso cuando la tensión es bien dramática, es mayormente el ambiente que produce la comedia cómica, con todo de lo que tiene de fantástico y melodramático la acción de esta obra. En las palabras de los últimos versos de la $\mathrm{La}$ devoción de la cruz, vemos confirmado el efecto de conciliación con que la comedia cómica termina. Inmergiendo al espectador en el mundo

${ }^{21}$ Estos tres movimientos son tipícos de una acción trágica, y en las tragedias calderonianas los citados movimientos se desarrollan durante toda la obra, concentrándose con mucho más profundidad que en La devoción.

${ }^{22}$ Pensamos, por ejemplo, en el dolor suprimido por David al perder a su hijo en los versos que cierran Los cabellos de Absalón. 
de la fantasía, tan típico de las comedias hagiográficas, Calderón no desea disipar el placer sentido por el espectador en los muchos relatos milagrosos, así como en el desenlace espectacular de la resurrección y la salvación celebradas en ese «felice fin». 


\section{BibLIOGRAFÍA}

Arellano, Ignacio, «Tragicidad y comicidad en la comedia de capa y espada: Marta la piadosa de Tirso de Molina», Bulletin Hispanique, 91, 1989, pp. 279-294.

Benabu, Isaac, «La devoción de la cruz y su "felice” fin", en Hacia Calderón: Quinto coloquio anglogermano, ed. Hans Flasche, Stuttgart, Franz Steiner, 1988, pp. 210-220.

Benabu, Isaac, Reading for the Stage: Calderón and his Contemporaries, Woodbridge, UK, Tamesis, 2003.

Benabu, Isaac, «La construcción del personaje teatral: el Duque de Ferrara en El castigo sin venganza», en El patrimonio del teatro clásico español: actualidad y perspectivas. ed. Germán Vega García-Luengos, Héctor Urzáiz Tortajada y Pedro Conde Parrado, Olmedo / Valladolid, Universidad de Valladolid y Ayuntamiento de Olmedo, 2015, pp. 233-242.

Calderón de la Barca, Pedro, La devoción de la cruz, ed. Sidney F. Wexler, Salamanca, Anaya, 1972.

Delgado Morales, Manuel, "Poetry and Spectacle in La devoción de la cruz», en The Calderonian Stage: Body and Soul, ed. Manuel Delgado Morales, Lewisburg, Bucknell University Press, 1997, pp. 55-68.

Olson, Elder, Theory of Comedy, Bloomington, Indiana University Press, 1968.

Parker, Alexander A., The Approach to the Spanish Drama of the Golden Age, London, The Hispanic and Luso-Brazilian Councils, 1957.

Parker, Alexander A., «Towards a Definition of Calderonian Tragedy», Bulletin of Hispanic Studies, 39, 1962, pp. 222-237.

Pring-Mill, Robert F., «Los calderonistas de habla inglesa y La vida es sueño», en Litterae Hispanae et Lusitanae, ed. Hans Flasche, Munich, Max Hueber Verlag, 1968, pp. 369-413.

SÁEz, Adrián, «Una aproximación a La devoción de la cruz: obra temprana de Calderón", en Contra los mitos y sofismos de la teoría literaria posmoderna, ed. Jesús G. Maestro e Inger Enkvist,Vigo, Academia del Hispanismo, 2010, pp. 217-239.

Téllez, Gabriel (Tirso de Molina), Marta la piadosa. Disponible en línea: $<$ http://www.comedias.org/tirso/marta.pdf> [12/09/2016].

VAREY, John E. «Imágenes, símbolos y escenografía en La devoción de la cruz», en Hacia Calderón: Segundo coloquio anglogermano, ed. Hans Flasche, Berlín, Walter de Gruyter, 1973, pp. 155-170.

Vega, Lope de, Arte nuevo de hacer comedias en nuestro tiempo, Buenos Aires, Espasa Calpe, 1948, pp. 11-19. 